\title{
Targeted Disruption of a Fungal G-Protein $\beta$ Subunit Gene Results in Increased Vegetative Growth but Reduced Virulence
}

\author{
Shin Kasahara and Donald L. Nuss \\ Center for Agricultural Biotechnology, University of Maryland Biotechnology Institute, University of Mary- \\ land, College Park 20742-4450, U.S.A. \\ Accepted 18 July 1997.
}

Targeted disruption of two G-protein $\alpha$ subunit genes in the chestnut blight fungus Cryphonectria parasitica revealed roles for the $\mathbf{G}_{\mathrm{i} \alpha}$ subunit $\mathbf{C P G}-1$ in fungal reproduction, virulence, and vegetative growth. A second $\mathbf{G}_{\alpha}$ subunit, CPG-2, was found to be dispensable for these functions. We now report the cloning and targeted disruption of a $C$. parasitica $G$-protein $\beta$ subunit gene. The deduced amino acid sequence encoded by this gene, designated $c p g b-1$, was found to share $66.2,65.9$, and $66.7 \%$ amino acid identity with $\mathbf{G}_{\beta}$ homologues from human, Drosophila, and Dictyostelium origins, respectively, but only $39.7 \%$ identity with the Saccharomyces cerevisiae $\mathbf{G}_{\beta}$ homologue STE4 product. Low stringency Southern hybridization failed to detect any related $G_{\beta}$ subunit genes in $C$. parasitica. Targeted disruption of $c p g b-1$ resulted in several of the changes previously reported to accompany disruption of the $C$. parasitica $G_{\mathrm{i} \alpha}$ subunit gene cpg-1. These included very significant reductions in pigmentation, asexual sporulation, and virulence. In contrast to results obtained for $G_{i \alpha}$ gene disruption, the reduction in virulence resulting from the disruption of a $\mathbf{G}_{\beta}$ gene was accompanied by increased, rather than decreased, vegetative growth on synthetic medium. The relevance of these results to mechanisms of fungal virulence is considered.

Additional keywords: hypovirulence, signal transduction.

Eukaryotic organisms perceive and respond to the external environment through a variety of transmembrane signaling mechanisms. A principal response pathway involves heterotrimeric $(\alpha \beta \gamma)$ GTP-binding proteins that are highly conserved among diverse eukaryotes (Gilman 1987). These protein complexes couple the activation of a large family of heptahelical transmembrane receptors with a limited number of effector enzymes, leading to the activation of regulatory cascades that subsequently results in appropriate changes in gene expression, cellular function, and metabolism (Dohlman et al. 1987). In the inactive form, the G-protein $\alpha$ subunit binds GDP with a high affinity, while the $\beta \gamma$ dimer serves to stabilize the complex. Activation of a G-protein coupled receptor by a variety

Corresponding author: Donald L. Nuss; E-mail: nuss@ umbi.umd.edu

Nucleotide and/or amino acid sequence data are to be found at GenBank under accession number U95139. of environmental stimuli, ranging from hormone ligands to light, results in a conformational change, exchange of GTP for GDP, and dissociation of the three subunits as $\alpha$-GTP and a $\beta \gamma$ heterodimer. Both the $\alpha$ subunit bound to GTP and the free $\beta \gamma$ dimer have been shown to interact with and alter the activity of a diverse set of effector molecules that include adenylyl cyclase, ion channels, phospholipase A2, and phospholipase C (Clapham and Neer 1993; Hamm and Gilchrist 1996). Hydrolysis of GTP to GDP results in signal termination and reassociation of the $\alpha$-GDP subunit with the $\beta \gamma$ heterodimer.

In higher eukaroytes, G-protein signaling has been implicated in mediating such complex biological processes as perception of taste, smell, and light, hormone action, chemotaxis, neurotransmission, cell proliferation, and differentiation (Gilman 1987; Dohlman et al. 1991) The mating pheromone response in the simple eukaryote Saccharomyces cerevisiae has provided a useful system for the detailed examination of relative roles played by $G_{\alpha}$ and $G_{\beta \gamma}$ subunits and for the identification of linked signaling cascade components (Hamm and Gilchrist 1996; Herskowitz 1987). In this system, it is the $G_{\beta \gamma}$ dimer that functions in transduction of the pheromone-binding signal while the $\alpha$ subunit serves as a negative regulator. Interestingly, the situation appears to be reversed in Schizosaccharomyces pombe, with the $\alpha$ subunit mediating the pheromone-binding signal (Isshiki et al. 1992). The role of G-protein signaling in the complex biological processes performed by filamentous fungi is less well understood. However, recent reports of the cloning and targeted disruption of genes encoding $G_{\alpha}$ subunits are providing significant new insights.

The cloning of $G_{\alpha}$ subunit genes has been reported for the following filamentous fungi: Aspergillus nidulans (Yu et al. 1996), Candida albicans (Sadhu et al. 1992), Coprinus congregatus (Kozak et al. 1995), Cryphonectria parasitica (Choi et al. 1995), Cryptococcus neoformans (Tolkacheva et al. 1994), Kluyveromyces lactis (Savinon-Tejeda et al. 1996), Neurospora crassa (Turner and Borkovich 1993), Pneumonocystis carinii (Smulian et al. 1996), and Ustilago maydis (Regenfelder et al. 1997). Until very recently, suggested roles for $G_{\alpha}$-linked signaling in filamentous fungi were limited to undefined involvement in mating. However, targeted disruptions of several fungal $\mathrm{G}_{\alpha}$ subunit genes are beginning to reveal roles for G-protein signaling in a wide range of fungal biological processes. Ivey et al. (1996) recently reported that disruption of the gene encoding the $N$. crassa $\mathrm{G}_{\mathrm{i} \alpha}$ homologue, gna-1, resulted in multiple phenotypes during the vegetative and sexual growth cycles, e.g., 
altered colony morphology, slower hyphal extension rates, delayed conidial maturity, and sex-specific loss of fertility. Four different $\mathrm{G}_{\alpha}$ subunit genes were recently disrupted in $U$. maydis (Regenfelder et al. 1997). While null mutants for three of the $G_{\alpha}$ genes gave no phenotype, disruption of $G_{\alpha}$ gene gna-3 resulted in loss of pheromone responsiveness (loss of mating) and a defect in pathogenic development. In this regard, several independent lines of evidence, including results of gene disruption studies, have indicated a role for G-protein signal transduction in virulence of the chestnut blight fungus Cryphonectria parasitica.

Interest in signal transduction in $C$. parasitica has been stimulated in large part by observations related to changes in fungal phenotype that result upon infection by virulenceattenuating hypoviruses (reviewed in Nuss 1996). Alterations associated with hypovirus infection can range from convenient laboratory markers, such as reduced pigment production, to reductions in vital functions, such as asexual and sexual reproduction, to reduced virulence, termed hypovirulence, a complex biological process of practical importance. Given the pleiotropic nature of these hypovirus-mediated phenotypic alterations, Choi et al. (1995) initiated the cloning of signal transduction components, leading to the identification of two $C$. parasitica Gprotein $\alpha$ subunit genes, designated cpg- 1 and cpg-2. The former was found to be $98 \%$ identical at the amino acid level to the previously cloned $\mathrm{G}_{\mathrm{i} \alpha}$ gene gna-l of $N$. crassa, while the latter was subsequently found to be most closely related to gna-3 of $U$. maydis. These authors also provided evidence that hypovirus infection of $C$. parasitica resulted in significantly reduced accumulation of the cpg-1 gene product CPG-1, as determined by Western (immunoblot) analysis. They further showed that transgenic co-suppression of CPG-1 accumulation in the absence of hypovirus infection also resulted in attenuation of fungal virulence. Wang and Nuss (1995) subsequently reported that cellulose-dependent induction of $C$. parasitica-encoded cellulases, enzymes with the potential for degrading plant host cell wall components during the infection process, is prevented by both hypovirus infection and CPG-1 co-suppression. Chen et al. (1996) showed that both hypovirus infection and CPG-1 cosuppression result in constitutively elevated cAMP levels, consistent with the prediction that CPG-1, like mammalian $G_{i \alpha}$ subunits, may function to negatively regulate adenylyl cyclase. These combined studies provided support for the proposal that fungal phenotypic alterations associated with hypovirus infections are mediated primarily through disruption of the CPG-1regulated, cAMP-linked signaling pathway. Consistent with this view, targeted disruption of cpg-1 (Gao and Nuss 1996) was shown to result in elevated cAMP levels and a set of phenotypic changes similar to, but more severe than, those caused by hypovirus infection. In contrast, cpg-2 disruptants exhibited only a slight reduction in growth rate and asexual sporulation and no significant reduction in virulence or other hypovirulenceassociated traits. These results led the authors to conclude that CPG-1 and CPG-2 serve quite distinct roles in fungal virulence, morphology, and reproduction.

In contrast to the recent progress in uncovering roles for $G_{\alpha}$ subunits in filamentous fungal signal transduction, information concerning the contribution of other fungal G-protein subunits to complex biological processes is severely limited. For example the cloning and characterization of a $G_{\beta}$ or $G_{\gamma}$ subunit gene has not been reported for any filamentous fun- gus. As an extension of our studies on G-protein signaling and fungal virulence, we now report the cloning and targeted disruption of a $C$. parasitica $\mathrm{G}_{\beta}$ subunit gene.

\section{RESULTS}

Cloning and characterization of a $C$. parasitica $\mathbf{G}_{\beta}$ gene.

Degenerate oligonucleotide primers corresponding to highly conserved $\mathrm{G}_{\beta}$ amino acid sequence domains (Gallagher and Gautam 1994) were designed to amplify $C$. parasitica $\mathrm{G}_{\beta}$ gene sequences by polymerase chain reaction (PCR). A single PCR amplicon of the predicted size of $0.8 \mathrm{~kb}$ was generated and confirmed by sequence analysis to encode a prospective $G_{\beta}$ subunit. Use of this amplicon as a hybridization probe to screen $C$. parasitica genomic and cDNA libraries resulted in the identification of three genomic and one cDNA clone candidates. Characterization of these independent clones revealed properties of the $C$. parasitica $\mathrm{G}_{\beta}$ gene designated cpgb-1 (Cryphonectria parasitica $\underline{\mathrm{G}}$ protein $\underline{\beta}$-subunit gene-1) as indicated in Figure 1.

The cpgb-1 coding region, including introns, consists of 1,497 nucleotides specifying a protein of 359 amino acids with a calculated molecular weight of 39,885. Comparison of genomic and cDNA clones of this gene revealed a total of four introns with consensus $5^{\prime}$ and $3^{\prime}$ splicing signal sequences (Choi et al. 1992) and a polyadenylation site located $671 \mathrm{nu}-$ cleotides past the TAG translation termination codon. Lowstringency Southern hybridization analysis failed to detect any gene sequences related to $c p g b-1$ in the $C$. parasitica genome, suggesting the presence of a single $G_{\beta}$ subunit gene in this filamentous fungus (data not shown).

Alignment analysis of the deduced $c p g b-1$ amino acid sequence revealed a high degree of sequence similarity with $G_{\beta}$ homologues of vertebrates, invertebrates, and lower eukaryotes (Fig. 2). Levels of 66.2, 65.9, and 66.7\% identity were observed with human, Drosophila, and Dictyostelium $\mathrm{G}_{\beta}$ sequences, respectively. Interestingly, the $c p g b-1$ protein product (CPGB-1) shared only $39.7 \%$ identity with the $S$. cerevisiae $\mathrm{G}_{\beta}$ homologue Ste4p. Amino acid residues identified by crystallographic analysis (Lambright et al. 1996; Sondek et al. 1996) as interacting with $G_{\alpha}$ subunits were found to be highly conserved among the five $G_{\beta}$ homologues, while those residues identified as interacting with the $\mathrm{G}_{\gamma}$ subunit varied considerably (Fig. 2).

\section{Targeted disruption of the $C$. parasitica cpgb-1 gene.}

A $c p g b-1$ disruption vector was constructed by replacing a portion of a 3.4-kb Pst I-PstI restriction fragment containing the $c p g b-1$ gene cloned into pBluescript II. As illustrated in Figure 3A, this involved replacement of a 183-nucleotide SacI-NcoI fragment that extended from the very $3^{\prime}$ end of exon 1 to the $3^{\prime}$ end of intron 1 with a $2.3-\mathrm{kb}$ cassette composed of the Escherichia coli hygromycin phosphotransferase gene ( $h p h$ ) flanked by the Aspergillus nidulans trpC promoter and terminator. Transformation was performed with a $4.7-\mathrm{kb}$ fragment containing the modified $c p g b-1$ gene that was released by digestion with SpeI (located within the pBluescript II multiple cloning sequence upstream of the PstI site) and $P v u I I$ (located within exon 4 of the $c p g b-1$ gene). Of 150 single-spored, hygromycin-resistant $C$. parasitica colonies recovered, six showed a similar set of altered phenotypic changes. Results of PCR and Southern blot analysis showed that three of 
cttgcattttcccttcccacaagcatcgatcccagctccagtctgctcaatcaaacccatccttcaatccaatccaatccaaacccacat -271 tcatccatccatctgttcggccaccttccttcccatcccctcccccatcgtccgtccgaccgattccattgaacaccacaaatttgtcaa -181 tcgacaacatcgtcggcggcttaccttgccgttccaacctgccccctccgcgcggtcgaccgcctctttctctctctttatttctctcg -91 cgttctctctctgcgtctcttgtccaatttcgaaccccttgtgcactggccgcgtctcctccctccctgcggcttgagcgctccccaag -1 ATGGACTCACAACGACCGAACGACGTCTCTCCCGAGGCGATGCAGGCGCGCATCCAGCAGGCACGGCGTGAAGCAGAGGGTCTCAAGGAC 90

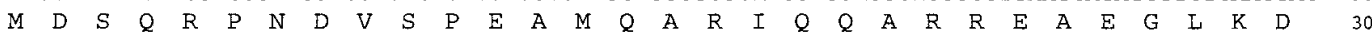
CGTATCAAGAGGAAGAAGGATGAGCTCGCCGACACCTCCCgtaagtctcgcaactatttccctctcaccgctcccgatcttgaacgatca 180 $\begin{array}{llllllllllllllllllll}R & I & K & R & K & K & D & E & L & A & D & T & S & L & \end{array}$ atcaatccatcattcaatcgtccaacaccagccgatcgactcatcgcgttcttttcctttgtgtttggccacgccgcccttatctctct 270 atctccctgtctctttccctcttccatggctgacgtgattaactcccagTCCGCGATGTCGCACACCGATCACACGAGGCGATTCCCAGG 361 $\begin{array}{lllllllllllllllllllll}R & D & V & A & H & R & S & H & E & A & I & P & R & 57\end{array}$ AACCAGTTGATGAAGACGAAACGGACACTGAAGGGCCACCTGGCCAAGATTTACGCGATGCACTGGTCCACCGACCGGAGGCATCTCGTC 451

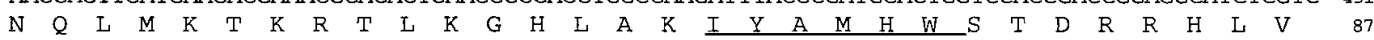
TCCGCCTCGCAGGACGGCAAGTTGATCATCTGGGATGCCTACACCACCAACAAGGTCCACGCCATCCCCCTCAGGTCCTCCTGGGTCATG 541 $\begin{array}{llllllllllllllllllllllllllllllllll}S & A & S & D & Q & G & K & L & I & I & W & D & A & Y & T & T & N & K & V & H & A & I & P & L & R & S & S & W & V & M & 117\end{array}$ ACCTGTGCCTACGCACCCAGCGGTAATTACGTTGCATGTGGTGGPCTGGACAACATCTGCTCCATCTACAACCTCAACCAGAACAGGGAT 631 $\begin{array}{lllllllllllllllllllllllllllllllll}T & C & A & Y & A & P & S & G & N & Y & V & A & C & G & G & L & D & N & I & C & S & I & Y & N & L & N & Q & N & R & D & 147\end{array}$ GGGCCCACACGCGTGGCCCGCGAGCTGTCCGGCCATGCCGGCTACCTGTCCTGCTGCCGATTCATCAACGACCGGAGCATCCTGACCTCG 721 $\begin{array}{lllllllllllllllllllllllllllllllllllllllll}G & P & T & R & V & A & R & E & L & S & G & H & A & G & Y & L & S & C & C & R & F & I & N & D & R & S & I & L & T & S & 177\end{array}$ TCAGGCGATATGACCTGCATGAAGTGGGATATCGAGACGGGCACGAAGCAGATCGAGTTTGCTGACCACCTCGGCGATGTCATGAGCATC 811

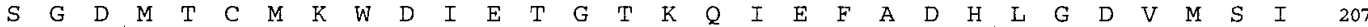
AGCCTCAACCCCACGAACCAAAACACCTTCATCTCCGGTGCTTGCGATGCCTTCGCCAAGCTCTGGGATATTCGGGCCGGCAAGGCTGTG 901 $\begin{array}{lllllllllllllllllllllllllllllll}\mathrm{S} & \mathrm{L} & \mathrm{N} & \mathrm{P} & \mathrm{T} & \mathrm{N} & \mathrm{Q} & \mathrm{N} & \mathrm{T} & \mathrm{F} & \mathrm{I} & \mathrm{S} & \mathrm{G} & \mathrm{A} & \mathrm{C} & \mathrm{D} & \mathrm{A} & \mathrm{F} & \mathrm{A} & \mathrm{K} & \mathrm{L} & \mathrm{W} & \mathrm{D} & \mathrm{I} & \mathrm{R} & \mathrm{A} & \mathrm{G} & \mathrm{K} & \mathrm{A} & \mathrm{V} & 237\end{array}$ CAGACTTTIGCGGGTCACGAGTCCGACATTAATGCCATCCAGTTCTTCCCCGATGGCCACAGCTTCGTGACTGGCTCCGACGACGCGACA 991 $\begin{array}{llllllllllllllllllllllllllllllllllllll}\mathrm{Q} & \mathrm{T} & \mathrm{F} & \mathrm{A} & \mathrm{G} & \mathrm{H} & \mathrm{E} & \mathrm{S} & \mathrm{D} & \mathrm{I} & \mathrm{N} & \mathrm{A} & \mathrm{I} & \mathrm{Q} & \mathrm{F} & \mathrm{F} & \mathrm{P} & \mathrm{D} & \mathrm{G} & \mathrm{H} & \mathrm{S} & \mathrm{F} & \mathrm{V} & \mathrm{T} & \mathrm{G} & \mathrm{S} & \mathrm{D} & \mathrm{D} & \mathrm{A} & \mathrm{T} & 267\end{array}$ TGCCGTCTCTTTGATATCCGCGCCGACCGGGAGCTCAACGTCTACGGCgtaagcattttcCcatccagaactgagtgcgaaagacatttg 1081 $\begin{array}{lllllllllllllllllllllll}C & R & L & F & D & I & R & A & D & R & E & L & N & V & Y & G\end{array}$

aagact tctcat gctgacgtctgett tcatttccagTCCGAATCCATTCTCTGCGGCATCACTTCTGTCGCCACATCCGTCTCCGGCCGA1172 $\begin{array}{lllllllllllllllllllllllllllll}S & E & S & I & L & C & G & I & T & S & V & A & T & S & V & S & G & R & 301\end{array}$

CTCCTTTTCGCAGGCTACGATGACTTCGAGTGCAAGgtacgtttccattacccagcttctatggggagccatcaacctgactgacatgcc 1262

L

acacagGTCTGGGATGTTACCCGGGGTGAGAAGGTTGGGTCTCTCGTCGGCCACGAGAACCGTGTCAGCTGCTTGGGCGTAAGCAACGAC 1352 $\begin{array}{llllllllllllllllllllllllllllll}V & W & D & V & T & R & G & E & K & V & G & S & L & V & G & H & E & N & R & V & S & C & L & G & V & S & N & D & 341\end{array}$

GGCATAAGTCTGTGCACAGGCTCCTGGGATTCATTGgtatgatctctccctatcgccattctggctttttcatgcacgtgacggtcgtgc 1442

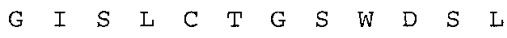

gagaggaacaaaaattgctaacactttggggaatagCTCAAAATCTGGGCGTACTAGaccgcagcttgacgacttcacgacggtcCcCgg 1532 $\mathrm{L} K \mathrm{~K}$ W A Y .

ggtagaacccggtctacggccgctttgcgttctcgattgctttcatggctctcttaattcacatgtgtacgcattttaattccacaagcg 1622 agccggcgcgtacaggacgaagtcacgaaaccccttccggacccaacaatcccgatccgatgacggccctaagccgctgcaacgacggcg 1712 aatctagtgtgcgacgtgtcaacttggcatctcccggcgctgggaaggctgtcggtcggatccgttggagcattcatactttttcgcgcc 1802 cccttatattacttctcgactgccataataccacgtcgaccttctatttttggctccgccctgaaatgcggtccaaactacccaggcgt 1892 cctctttcttcttcttttcttctattccacagtggtgatgactatccgatggggaggagatcggagagctgagaattgcgaggtggt 1982 catgagcgetgccgacggattccgaccggcagcgaggcgcttgtgacgaggtcgggtcggagcggcgaatcgtacgcctcgaccgtaacg 2072 ctgaaattgtttccaggagttgaggaaaattgtcatttccgaaatgctcgtacgaaggtatctgcagcagccaacaataaactcgatata 2162 tcatgggTttgtcgcttcctctcaacggggcgtaagaggatgatgaggagagcttcgggagcacgggaccctcttgccacagcgaaaggg 2252

Fig. 1. Nucleotide sequence of the Cryphonectria parasitica G-protein $\beta$ subunit gene $c p g b-1$. Deduced amino acid sequence is shown below nucleotide sequence and numbered at right. Introns are indicated in lowercase within the coding region. Conserved $5^{\prime}$ and $3^{\prime}$ splicing sites are indicated in bold; the internal consensus signal sequences are underlined. Potential CAAT sequences ( -296 to -283$)$ are underlined within the $5^{\prime}$ noncoding promoter region. Amino acid sequences IYAMHW and GHENRV used for designing degenerate polymerase chain reaction primers are underlined. Translation termination codon TAG is indicated by a dot followed by an underlined consensus polyadenylation signal at positions 2148 to 2153 and a bold uppercase $\mathrm{T}$ at position 2170 indicating the polyadenylation site for the $c p g b-1$ transcript. The GenBank accession number for the $c p g b-1$ sequence is $\mathrm{U} 95139$. 
the putative disruptants, designated $\Delta \mathrm{G}_{\beta}-\mathrm{a}, \Delta \mathrm{G}_{\beta}-\mathrm{b}$, and $\Delta \mathrm{G}_{\beta}-\mathrm{c}$, each contained a single copy of the disruption vector integrated at the cpgb-1 locus (Fig. 3B). Hybridization of Pst I-digested genomic DNA with a probe corresponding to the $5^{\prime}$ noncoding region and exon 1 of $c p g b-1$ (probe 1) revealed a single hybridizing band for both wild-type and disruptant DNA, but of different sizes (Fig. 3B). The 3.4-kb band observed for EP155 DNA was replaced by a $2.1-\mathrm{kb}$ band for $\Delta \mathrm{G}_{\beta}-\mathrm{a}, \Delta \mathrm{G}_{\beta}-\mathrm{b}$, and $\Delta \mathrm{G}_{\beta}-\mathrm{c}$ DNAs, consistent with a double cross-over event during homologous recombination. Additionally, hybridization of the blot with a probe corresponding to the $h p h$ cassette (probe 2) revealed a single, predicted, 3.4-kb band in all three disruptant DNAs (Fig. 3B). Northern (RNA) analysis revealed the presence of two cpgb-1-related transcripts of 3.5 and $2.5 \mathrm{~kb}$ in RNA prepared from strain EP155 (Fig. 4). Neither transcript was present in the RNAs isolated from the three disruptants.

\section{Phenotypic characterization of cpgb-1 disruptants.}

Disruption of $c p g b-1$ had a pronounced effect on colony morphology (Fig. 5). $\Delta \mathrm{G}_{\beta}$ colonies grown on PDA were distinguished by a significant reduction in orange pigment pro- duction, except for a small area in the older center of the colony, and the absence of normal aerial hyphae. Growth of the disruptants was examined under three different conditions and compared with that of untransformed strain EP155, the isogenic, hypovirus-infected strain EP713, and a $\mathrm{G}_{\mathrm{i} \alpha}$ cpg-1 gene disruptant, G1-1. As previously reported, hypovirusinfected colonies grown on PDA expanded at an approximately $20 \%$ slower rate than the isogenic virus-free strain (Hillman et al. 1990), while disruption of cpg-1 resulted in a 50 to $70 \%$ reduction in expansion rate on this medium (Gao and Nuss 1996). In contrast, colony expansion rates for each of the $\mathrm{G}_{\beta}$ disruptants were not significantly different from that of the untransformed control strain (EP155) (Table 1; Fig. 5). However, measurement of colony mass under two different growth conditions revealed notable differences. When colonies were grown on cellophane membranes overlaying PDA, mycelial mass was reduced by over $60 \%$ as a result of hypovirus infection and by nearly $90 \%$ as a result of cpg- 1 deletion. Unexpectedly, a significant increase (40 to 50\%) in mycelial mass (wet weight), relative to strain EP155, was observed for the $c p g b-1$ disruptants. A similar trend was observed for
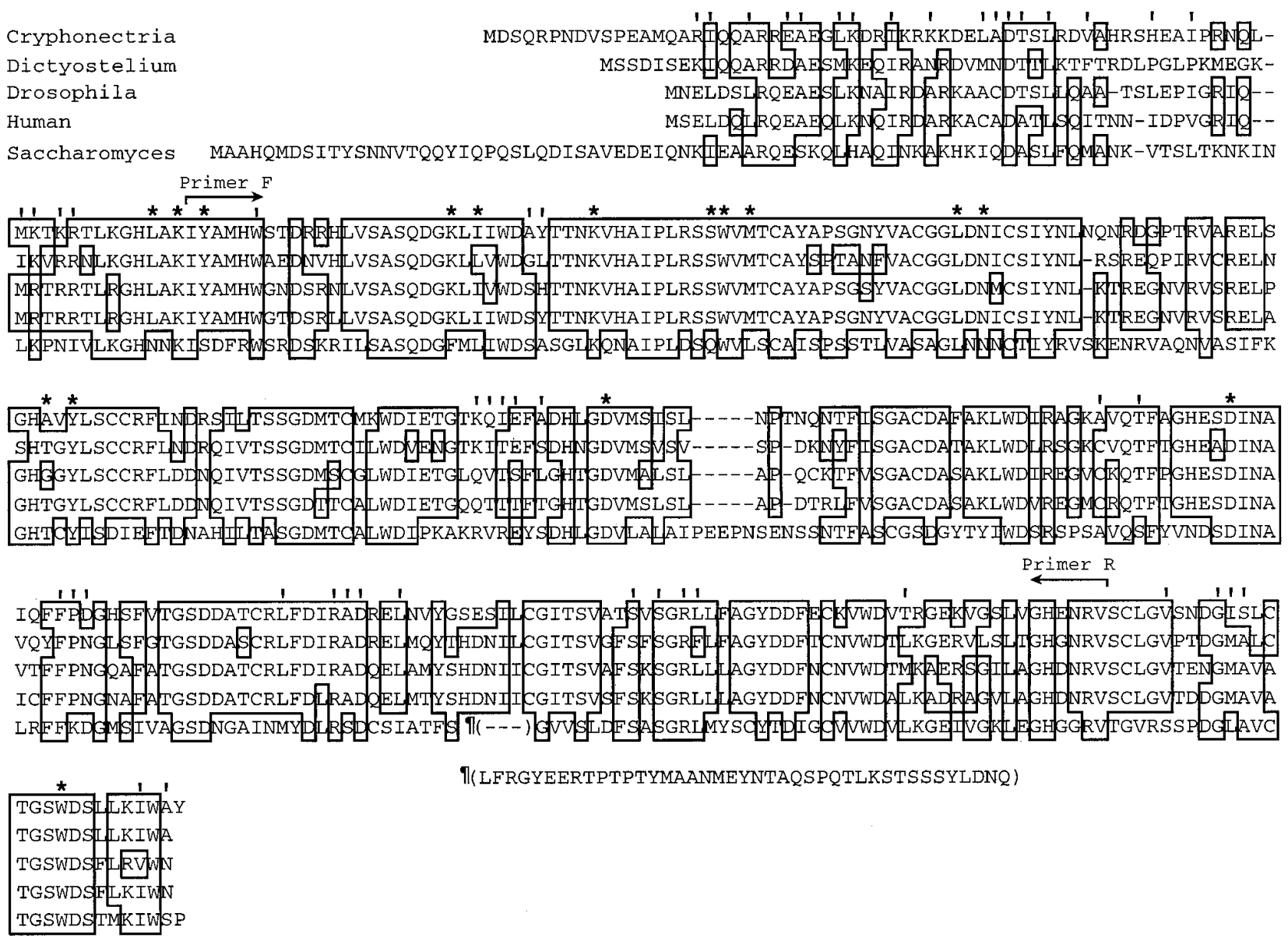

П(LFRGYEERTPTPTYMAANMEYNTAQSPQTLKSTSSSYLDNQ)

Fig. 2. Alignment of the deduced CPGB-1 amino acid sequence with amino acid sequences of $\mathrm{G}_{\beta}$ homologues from distantly related organisms. Amino acid residues that are identical in three of the five homologues are boxed. Conserved amino acid residues used for designing polymerase chain reaction primers (primer $\mathrm{F}$ for the forward orientation and primer $\mathrm{R}$ for the reverse orientation) are indicated by overlines. Residues that contact $\mathrm{G}_{\alpha}$ subunits are marked with asterisks, while residues that contact $\mathrm{G}_{\gamma}$ subunits are indicated by wedges (Lambright et al. 1996; Sondek et al. 1996). Sequences for the human (Fong et al. 1986), Dictyostelium (Lilly et al. 1993; accession no. J04083), Drosophila (Yarfritz et al. 1988; accession no. X73641) and Saccharomyces cerevisiae (Whiteway et al. 1989; accession no. M23982) $\mathrm{G}_{\beta}$ genes were obtained from GenBank. 
growth in a rich liquid medium, PD broth. The relative amount of mycelial mass, determined as dry weight, produced for the hypovirus-infected and $\Delta c p g-1$ cultures was not significantly different from the values obtained from the PDA-grown cultures, approximately 25 and $40 \%$ reductions, respectively. However, by day 5 , mycelial dry weight produced by the $\Delta \mathrm{G}_{\beta}$ cultures was found to be over $200 \%$ of the value obtained for strain EP155. Thus, disruption of $C$. parasitica $\mathrm{G}_{\alpha}$ genes results in either a slight ( $\Delta c p g-2)$ (Gao and Nuss 1996) or a marked ( $\Delta c p g$ 1) (Table 1; Gao and Nuss 1996) reduction in growth on synthetic media, while disruption of the only detectable $C$. parasitica $\mathrm{G}_{\beta}$ subunit gene causes a significant increase in the production of mycelial mass on some synthetic media (Table 1).
Additional morphological changes resulting from cpgb-1 disruption were revealed by microscopic examination. Hyphae of the $\mathrm{G}_{\beta}$ disruptant colonies exhibited much less branching than wild-type hyphae. This was most notable at the growing edge of the colony (Fig. 6A,B). This resulted in lower cell density in the younger, rapidly advancing edge of the colony. However, inspection of more mature portions of the colony revealed increasing hyphal density, increased branching, and the formation of parallel hyphal arrays (Fig. 6C). This resulted in the formation of a very dense mycelial mat that was easily peeled as a unit from the agar surface. This condensation of hyphae appears to account for the increased accumulation of mycelial mass observed for the $G_{\beta}$

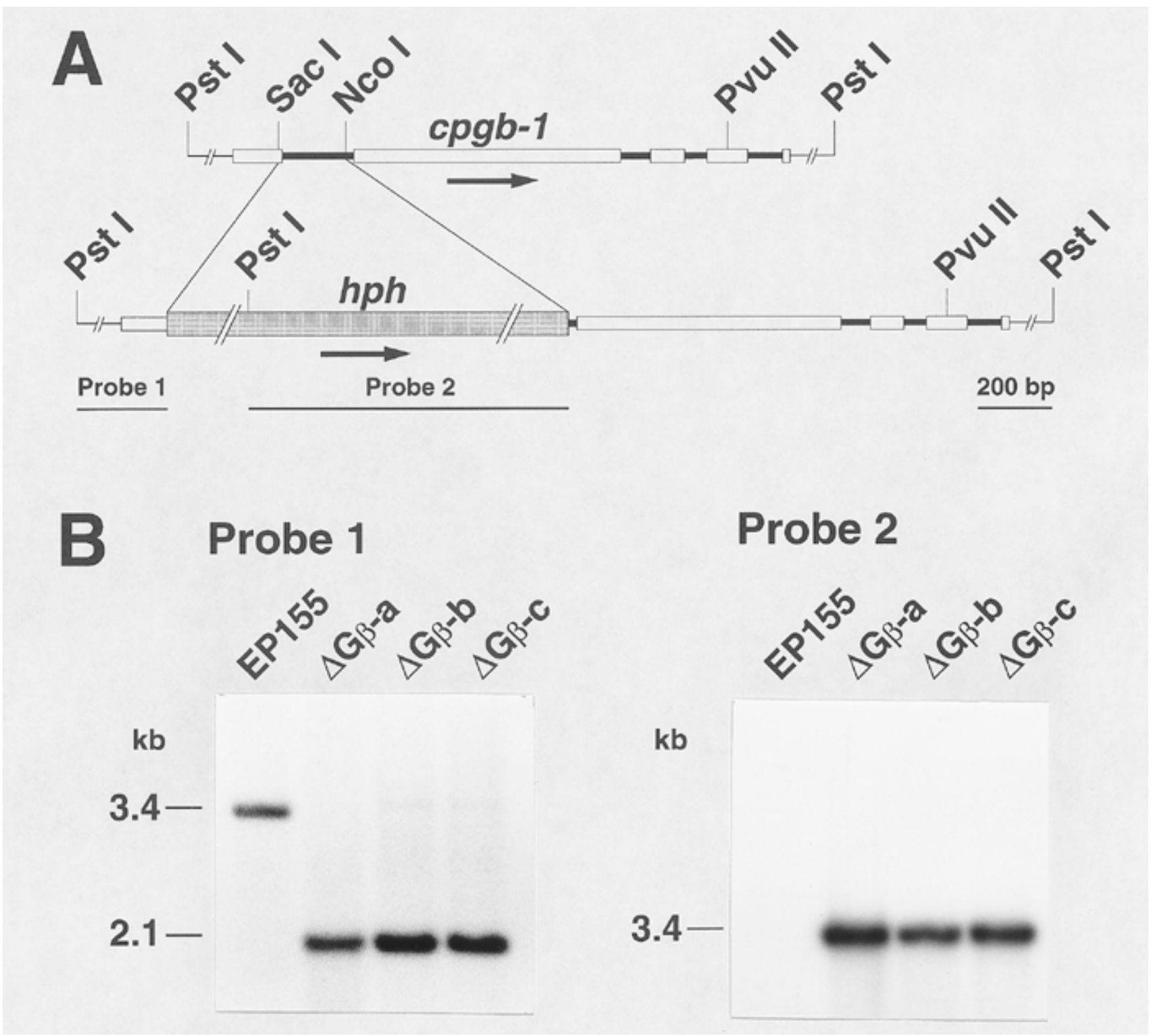

Fig. 3. Disruption of $c p g b-1$. A, Construction of a cpgb-1 disruption vector. The five exons constituting the cpgb-1 coding region are indicated by open boxes, while the four introns are depicted as black bars. The disruption vector was constructed by replacing a 183-bp SacI-NcoI fragment that extended from the $3^{\prime}$ end of exon 1 to the $3^{\prime}$ end of intron 1 with a 2.3-kb cassette composed of the Escherichi coli hygromycin phosphotransferase gene ( $\mathrm{hph}$ ) flanked by the Aspergillus nidulans trpC promoter and terminator. Portions of the vector used as probes for Southern blot analysis are indicated below the map. B, Results of Southern blot analyses for $c p g b-1$ disruptants. Genomic DNA was prepared from untransformed strain EP155 and three independent $c p g b-1$ disruptants designated $\Delta \mathrm{G}_{\beta}-\mathrm{a}, \Delta \mathrm{G}_{\beta}$-b, and $\Delta \mathrm{G}_{\beta}-\mathrm{c}$, digested with Pst $\mathrm{I}$, separated on a $1 \%$ agarose gel, and transferred to a Nytran Plus membrane. Probes used for hybridization are indicated in $\mathbf{A}$ and the estimated sizes of the hybridizing bands are indicated at the left. 
disruptants grown on cellophane overlays, or in rich liquid medium. Additional studies are required to more fully understand the basis for the micromorphological alteration associated with cpgb-1 disruption.

Gao and Nuss (1996) recently reported that disruption of cpg-1 resulted in loss in the ability to produce asexual spores (conidia) and in the ability to invade host chestnut tissue, while disruption of $c p g-2$ had little to no effect on these processes. Examination of $\Delta c p g b-1$ mutants revealed a significant $\left(10^{-5}\right.$ to $\left.10^{-6}\right)$, but incomplete, reduction in conidiation (data not shown). Viable conidia could be recovered from the lightly pigmented central portion of old PDA-grown cultures. An examination of virulence revealed a significant reduction in size of cankers formed by $\Delta \mathrm{G}_{\beta}$ strains relative to the control strain (Table 2). By 4 weeks after inoculation, cankers caused by the $c p g b-1$ disruptant strains had expanded to less than $10 \%$ the size of control virulent-strain cankers. Although the $\Delta \mathrm{G}_{\beta}$ strains were not reduced in virulence to quite the extent exhibited by the hypovirus-infected strain or the $\Delta c p g-1$ isolates, it is noteworthy that the reduced canker-forming ability caused by $c p g b-1$ disruption was not accompanied by a general debilitation or reduced growth phenotype.
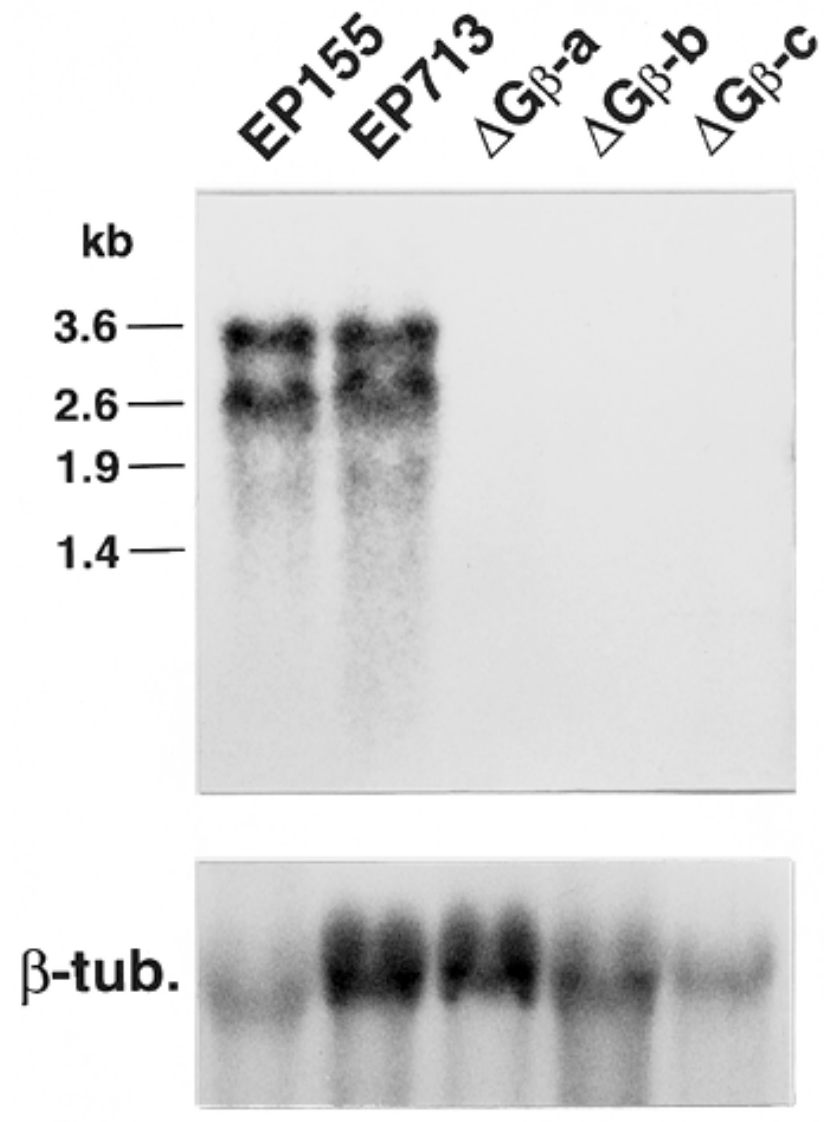

Fig. 4. Northern (RNA) hybridization analyses of $c p g b-1$ transcript accumulation in wild-type strain EP155 and $\Delta c p g b-1$ disruptants $\Delta \mathrm{G}_{\beta}-\mathrm{a}, \Delta \mathrm{G}_{\beta}-\mathrm{b}$, and $\Delta \mathrm{G}_{\beta}-\mathrm{c}$. Total RNA ( $15 \mu \mathrm{g}$ per well) from each strain was analyzed. The blot was hybridized with a ${ }^{32} \mathrm{P}-\mathrm{cDNA}$ copy of the entire $c p g b-1$ coding region. Positions of RNA size markers (Promega, Madison, WI) are indicated at left. After hybridization, the blot was stripped and hybridized with a Cryphonectria parasitica $\beta$-tubulin gene cDNA probe (Choi et al. 1992).

\section{DISCUSSION}

A role for G-protein signaling in diverse biological processes in the chestnut blight fungus was first suggested by the observation that hypovirus infection resulted in reduced accumulation of the $\mathrm{G}_{\mathrm{i} \alpha}$ subunit CPG-1. A correlation was established between reduced accumulation of this signaling component and hypovirus-mediated reductions in pigmentation, asexual sporulation, female fertility, the induction of several fungal genes (lac-1 and $c b h-1)$, and virulence (Choi et al. 1995; Chen et al. 1996). This correlation was further strengthened by targeted disruption of $C$. parasitica genes cpg- 1 and cpg-2, encoding $\mathrm{G}_{\alpha}$ subunits $\mathrm{CPG}-1$ and CPG-2, respectively (Gao and Nuss 1996). While cpg-2 disruption had little or no effect on the processes listed above, disruption of cpg-1 resulted in a set of phenotypic traits similar to, but more severe than, those caused by hypovirus infection. This report extends these observations by describing the first cloned $\mathrm{G}_{\beta}$ subunit gene for a pathogenic filamentous fungus, cpgb-1, and by showing that disruption of this gene also results in some of the same phenotypic changes that are observed after hypovirus infection or cpg-1 disruption, i.e., reduced pigmentation, reduced conidiation, and reduced virulence (Fig. 5; Table 2). These results provide additional evidence for the involvement of G-protein signaling in hypovirus-mediated alteration of fungal phenotype and in the regulation of multiple vital biological processes in this filamentous fungus. A notable difference in the phenotypic consequences of cpg- 1 and cpgb- 1 disruptions is that, in the latter case, reduced virulence is not accompanied by a severely reduced growth phenotype. This result points to expected differences in the influence of $G_{\alpha}$ and $\mathrm{G}_{\beta \gamma}$ subunits on effector molecules and signaling pathways and demonstrates that reduced virulence resulting from alteration of G-protein signaling in C. parasitica is not simply due to a general decrease in vegetative growth or viability.

Comparative amino acid sequence analyses for an increasing number of cloned fungal $G_{\alpha}$ genes are beginning to define subunit families. Based on similarities in gene organization and amino acid similarity for Gna- 1 of $N$. crassa (Turner and Borkovich 1993), CGP $\alpha 1$ of Coprinus congregatus (Kozak et al. 1995), and CPG-1 of $C$. parasitica (Choi et al. 1995), Ivey et al. (1996) suggested the existence of a fungal $G_{i \alpha}$ family. This prospective family has recently been extended by the reported cloning of two additional $\mathrm{G}_{\mathrm{i} \alpha}$ subunit homologue genes, fadA from Aspergillus nidulans (Yu et al. 1996) and gpa-1 from Ustilago maydis (Regenfelder et al. 1997). Ivey et al. (1996) has also made the point that a $\mathrm{G}_{\mathrm{i} \alpha}$ homologue gene appears to be absent in the Saccharomyces cerevisiae or Schizosaccharomyces pombe genomes and put forward the hypothesis that the $\mathrm{G}_{\mathrm{i} \alpha}$ family may have evolved within the filamentous fungi. The availability of the cpgb-1 deduced amino acid sequence now allows a comparison of the relatedness of a $\mathrm{G}_{\beta}$ subunit from a filamentous fungus with $\mathrm{G}_{\beta}$ homologues from higher and other lower eukaryotes. As indicated in Figure 2, the CPGB-1 sequence is considerably more closely related to a human $\mathrm{G}_{\beta}$ homologue than it is to the $S$. cerevisiae $\mathrm{G}_{\beta}$ homologue Ste4p. It will be interesting to compare sequences of $\mathrm{G}_{\beta}$ homologues from other filamentous fungi as they become available. Based on the limited sequence information currently available, it would appear that filamentous fungi may offer certain advantages over other commonly 
studied lower eukaryotes as experimental systems with which to examine detailed mechanistic studies of G-protein function.

Available evidence suggests that the genomes of several lower eukaryotes, including S. pombe (Kim et al. 1996) and Dictyostelium (Lilly et al. 1993), contain a unique $\mathrm{G}_{\beta}$ subunit gene. Results of Southern hybridization analysis with cpgb-1- specific probes at very low stringency were also consistent with the presence of a single $G_{\beta}$ subunit gene in the filamentous fungus $C$. parasitica (Fig. 3B and data not shown). However, the absence of a hybridization signal cannot be used to formally exclude the possible existence of additional $G_{\beta}$ subunit genes. Interestingly, two cpgb-1-specific transcripts

\section{EP155}
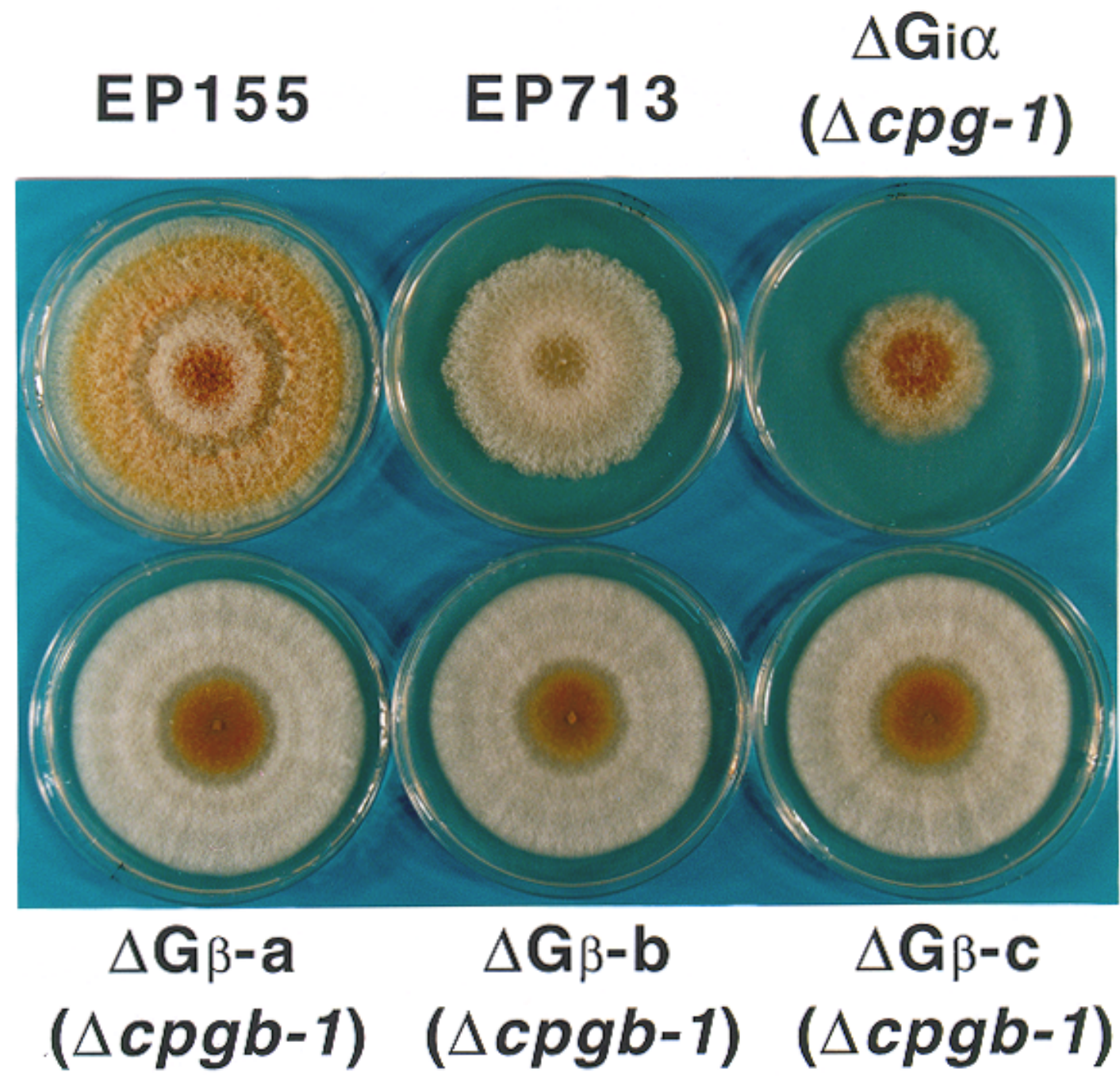

Fig. 5. Colony morphology of wild-type strain EP155 and cpgb-1 disruptants $\Delta \mathrm{G}_{\beta}-\mathrm{a}, \Delta \mathrm{G}_{\beta}$-b, and $\Delta \mathrm{G}_{\beta}$-c. When grown on potato dextrose agar, $\Delta c p g b-1$ disruptants exhibited a colony expansion rate similar to that of strain EP155. However, the disruptant colonies were significantly reduced in orange pigmentation, except for a small area in the colony's mature center. It was from the orange center region that conidia could be recovered. Disruptant colonies also failed to form normal aerial hyphae, but rather formed a dense mat that could be peeled from the agar as a unit. A cpg-1 disruptant, strain G1-1, was included at the upper right corner for point of reference. Colonies were incubated for 7 days in a growth chamber at $25^{\circ} \mathrm{C}$ set for a 16 -h photoperiod at approx. $2,000 \mathrm{~lx}$.

Table 1. Effect of $c p g b-1$ disruption on hyphal growth under three different conditions ${ }^{\mathrm{a}}$

\begin{tabular}{|c|c|c|c|c|c|c|c|c|c|}
\hline \multirow[b]{2}{*}{ Strains $^{\mathbf{b}}$} & \multicolumn{3}{|c|}{ On PDA plates $(\mathbf{m m} \pm \mathrm{SD}$, diameter $)$} & \multicolumn{3}{|c|}{$\begin{array}{l}\text { On PDA cellophane plates } \\
(\mathrm{mg} \pm \mathrm{SD} \text {, wet weight })\end{array}$} & \multicolumn{3}{|c|}{$\begin{array}{c}\text { In liquid PD broth } \\
\text { (mg } \pm \text { SD, dry weight })\end{array}$} \\
\hline & Day 3 & Day 5 & Day 7 & Day 3 & Day 5 & Day 7 & Day 3 & Day 5 & Day 7 \\
\hline EP155 & $31.7 \pm 0.5$ & $56.5 \pm 1.0$ & $77.3 \pm 1.0$ & $35.7 \pm 4.0$ & $142.8 \pm 11.4$ & $378.4 \pm 29.1$ & $4.5 \pm 0.1$ & $15.5 \pm 0.7$ & $44.4 \pm 7.3$ \\
\hline EP713 & $24.8 \pm 0.8$ & $44.8 \pm 0.8$ & $59.7 \pm 2.3$ & $31.0 \pm 1.9$ & $52.3 \pm 5.4$ & $137.2 \pm 22.5$ & $3.6 \pm 0.3$ & $11.9 \pm 1.9$ & $32.2 \pm 1.9$ \\
\hline$\Delta \mathrm{G}_{\beta}-\mathrm{a}$ & $29.0 \pm 1.0$ & $52.0 \pm 3.6$ & $74.3 \pm 3.1$ & $96.7 \pm 18.8$ & $213.7 \pm 3.8$ & $530.0 \pm 10.0$ & $5.3 \pm 0.7$ & $31.1 \pm 6.8$ & $55.3 \pm 10.1$ \\
\hline$\Delta \mathrm{G}_{\beta}-\mathrm{b}$ & $27.7 \pm 3.5$ & $54.3 \pm 2.5$ & $74.6 \pm 3.2$ & $89.1 \pm 4.8$ & $207.3 \pm 9.3$ & $534.0 \pm 28.6$ & $6.0 \pm 0.7$ & $33.5 \pm 4.1$ & $57.5 \pm 7.4$ \\
\hline$\Delta \mathrm{G}_{\beta}-\mathrm{c}$ & $29.7 \pm 1.2$ & $53.3 \pm 0.6$ & $72.3 \pm 2.9$ & $87.5 \pm 7.4$ & $202.7 \pm 15.3$ & $530.1 \pm 33.1$ & $5.7 \pm 0.9$ & $34.1 \pm 2.1$ & $58.5 \pm 2.2$ \\
\hline$\Delta \mathrm{G}_{\mathrm{i} \alpha}(\Delta c p g-1)$ & $12.0 \pm 0$ & $23.5 \pm 0.6$ & $35.8 \pm 1.7$ & $3.1 \pm 0.4$ & $17.3 \pm 3.8$ & $45.8 \pm 17.1$ & $3.1 \pm 0.5$ & $9.5 \pm 3.3$ & $26.9 \pm 3.9$ \\
\hline
\end{tabular}

${ }^{a}$ Measurements were taken at days 3,5, and 7 after inoculation. Growth conditions included $25 \mathrm{ml}$ of potato dextrose agar (PDA) in a standard, 87-mm petri dish, PDA overlaid with sterilized cellophane, and liquid PD broth. Values represent the mean \pm standard deviation of a minimum of four replicates.

${ }^{\mathrm{b}}$ Strains were tested in parallel. These included wild-type strain EP155, isogenic strain containing hypovirus CHV1-713, cpgb-1 disruptants $\triangle \mathrm{G}_{\beta}-\mathrm{a}, \Delta \mathrm{G}_{\beta}$ $\mathrm{b}$, and $\Delta \mathrm{G}_{\beta} \mathrm{c}$, and $\operatorname{cpg}-1$ disruptant $\mathrm{G} 1-1$. 
3.5 and $2.5 \mathrm{~kb}$ in size were detected by Northern analysis (Fig. 4). The fact that both transcripts were undetectable in RNA preparations from $c p g b-1$ disruptants indicates that both transcripts are derived from the $c p g b-1$ locus and, again, is consistent with the notion that $C$. parasitica encodes a single $G_{\beta}$ subunit. The mechanism responsible for the generation of two $c p g b-1$ transcripts is currently under investigation.

The detection of a single $G_{\beta}$ subunit gene raised the concern that $c p g b-1$ disruption would possibly be a lethal event or, at least, negatively affect viability. Disruption of $c p g b-1$ did result in reductions in fungal pigmentation, conidiation, and virulence (Fig. 5; Table 2). Unexpectedly, however, cpgb-1 disruptants

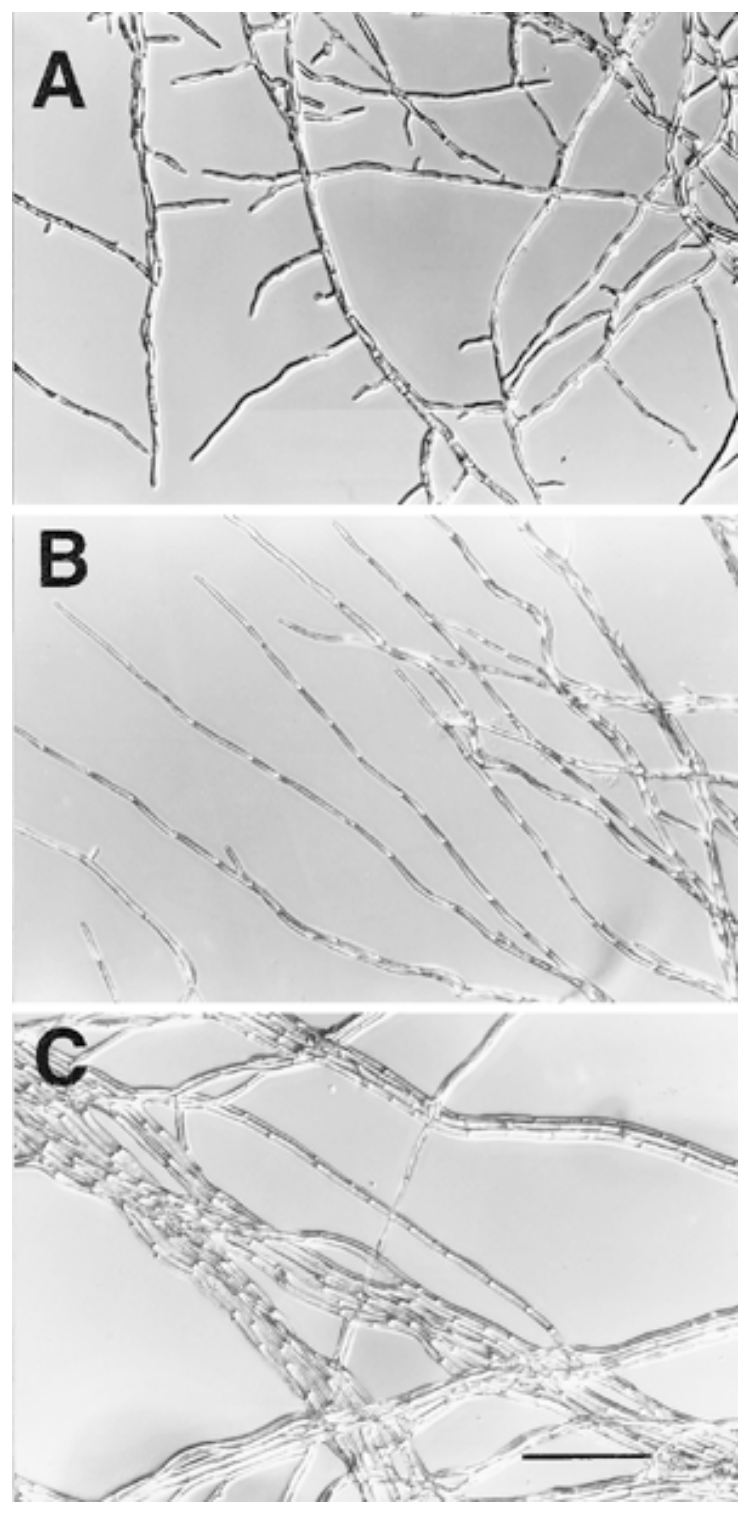

Fig. 6. Microscopic examination of $c p g b-1$ disruptants. A, Hyphae of wildtype Cryphonectria parasitica strain EP155 at growing edge of a colony shown as a control. $\mathbf{B}$, Hyphae of disruptant $\Delta \mathrm{G}_{\beta}$-a also at growing edge of a colony, with reduced level of branching. $\mathbf{C}$, Hyphae of disruptant $\Delta \mathrm{G}_{\beta}$-a at a position approximately $1 \mathrm{~mm}$ in from the growing edge of a colony. Parallel hyphae are bundled. These structures were absent from the EP155 colony. Size bar shown at the right bottom corner of $\mathbf{C}=60 \mu \mathrm{m}$. Photographs were taken under Nomarski optics at a magnification of $\times 1,000$. actually exhibited an increased vegetative growth phenotype (Table 1), rather than the decreased growth exhibited by the cpg1 disruptants. Microscopic examination of the $\mathrm{G}_{\beta}$ disruptants revealed the formation of bundles of parallel hyphal arrays that form a dense mycelial mat on the surface of the agar growth medium. The apparent propensity of the $\Delta \mathrm{G}_{\beta}$ disruptants to grow on, rather than to penetrate into, the agar surface, as is observed for wild-type $C$. parasitica, may be related to the limited cankerforming ability of the $c p g b-1$ disruptants on chestnut tissue. Although colony morphology is clearly altered by $c p g b-1$ disruption, the accumulation of mycelial mass is actually increased relative to the wild-type control. The observation that disruption of a gene encoding a signal transduction component results in significantly reduced virulence without an accompanying reduction in vegetative growth on synthetic medium also has some implications for current views of fungal virulence mechanisms.

A strict definition of a fungal virulence factor would insist that disruption of the corresponding gene results in reduced virulence without affecting other cellular processes. Since loss of virulence resulting from disruption of the $\mathrm{G}_{\mathrm{i} \alpha}$ gene cpg-l is also accompanied by reduced vegetative growth, loss of conidiation, and female infertility, CPG-1 would not be considered a virulence factor under this definition. Similarly, even though disruption of $c p g b-1$ results in reduced virulence in the absence of a reduced growth phenotype, accompanying alterations in conidiation and pigmentation would also preclude CPGB-1 from being considered a virulence factor. However, in making such distinctions one must consider that the expression of putative virulence factors in response to extracellular chemical and physical cues during the infection process must depend on a variety of regulatory pathways that are able to perceive and process this information. Moreover, such signaling pathways are often interconnected (cross-regulated) and may regulate multiple biological processes. Thus, within this context, the importance of a regulatory pathway for virulence cannot be disregarded simply because the disruption of a gene encoding a functional component of that pathway alters multiple processes. Although this issue will receive considerable future debate, the results presented in this and related reports (Choi et al. 1995; Chen et al. 1996; Wang and Nuss 1995; Gao and Nuss 1996) clearly show that an intact CPG-1/ CPGB-1-linked signaling pathway is required for $C$. parasitica virulence. In a less restrictive view of fungal virulence, Yoder and Turgeon (1996) recently noted that an understanding of the molecular basis of fungal disease requires (i) the identification of fungal gene products or metabolites that are essential for pathogenic processes and (ii) an ability to distinguish these factors from bystander molecules that are

Table 2. Mean canker areas induced on dormant chestnut stems by virulent strain EP155, isogenic hypovirus infected strain EP713, three cpgb-1 disruptants $\triangle \mathrm{G}_{\beta}-\mathrm{a}, \Delta \mathrm{G}_{\beta}$-b, and $\triangle \mathrm{G}_{\beta}$-c, and cpg-1 disruptant $\mathrm{G} 1-1^{\mathrm{a}}$

\begin{tabular}{lrrr}
\hline & \multicolumn{3}{c}{ Mean canker area \pm SD $\left(\mathbf{c m}^{2}\right)$} \\
\cline { 2 - 4 } Strains or mutants & \multicolumn{1}{c}{ 2 weeks } & \multicolumn{1}{c}{ 3 weeks } & 4 weeks \\
\hline EP155 & $11.95 \pm 3.77$ & $24.62 \pm 8.79$ & $45.42 \pm 15.1$ \\
EP713 & $1.58 \pm 0.60$ & $1.67 \pm 0.62$ & $1.75 \pm 0.55$ \\
$\Delta \mathrm{G}_{\beta}$-a & $2.82 \pm 1.40$ & $2.89 \pm 1.46$ & $3.63 \pm 2.68$ \\
$\triangle \mathrm{G}_{\beta}-\mathrm{b}$ & $2.83 \pm 0.86$ & $3.26 \pm 3.26$ & $3.58 \pm 1.48$ \\
$\triangle \mathrm{G}_{\beta}-\mathrm{c}$ & $2.77 \pm 1.25$ & $3.64 \pm 1.93$ & $3.92 \pm 2.48$ \\
$\triangle \mathrm{G}_{\mathrm{i} \alpha}(\Delta$ cpg-1) & $0.11 \pm 0.21$ & $0.13 \pm 0.26$ & $0.13 \pm 0.26$ \\
\hline
\end{tabular}

${ }^{a}$ Mean \pm standard deviation of 10 replicates was determined at 14,21 , and 28 days post inoculation. 
present, but not critical for disease progression. We would expand the first requirement to include the identification of environmental/chemical cues and signaling pathways that coordinately regulate an array of putative virulence factors throughout the infection process.

Since both G-protein $\alpha$ subunits and $\beta \gamma$ dimers can influence a variety of effector molecules and most eukaryotic organisms encode multiple G-protein subunits, assignment of an individual G-protein subunit to a specific functional role can be challenging. The availability of a cloned unique $C$. parasitica $\mathrm{G}_{\beta}$ subunit gene, multiple cloned $\mathrm{G}_{\alpha}$ subunits genes, and corresponding disruptant strains will now allow a detailed examination of the dynamics and possible coordinated regulation of G-protein subunit accumulation (Rudolph et al. 1996; Hermouet et al. 1993) and their relative roles in complex fungal biological processes, including virulence. It will be of considerable interest to determine whether the reduced accumulation of CPG-1 observed in hypovirus-infected strains is a primary effect of virus infection or a secondary effect due to virus-mediated alteration of other Gprotein signaling components, e.g., CPGB-1.

\section{MATERIALS AND METHODS}

\section{Fungal strains and growth conditions.}

C. parasitica strains EP155 (ATCC 38755, virulent, mycovirus-free), EP713 (ATCC 52571, isogenic to EP155, hypovirulent, contains prototypic hypovirus CHV1-713) and G11 (strain EP155 in which the $\mathrm{G}_{\mathrm{i} \alpha}$ gene cpg-1 was disrupted) (Gao and Nuss 1996) were maintained on Difco (Detroit, MI) potato dextrose agar (PDA) as described (Hillman et al. 1990).

\section{Cloning and characterization of cpgb-1.}

C. parasitica cDNA and genomic library screening, subcloning, and other routine procedures were performed according to standard protocols (Sambrook et al. 1989). Gene organization, including intron/exon identification, was determined as described (Choi et al. 1992). Sequence analysis was performed by the dideoxynucleotide termination method (Sanger et al. 1977) with the Perkin-Elmer Applied Biosystems (Foster City, CA) Taq DyeDeoxy terminator cycle sequencing kit and a model 373A DNA sequencing apparatus. The probe used to screen $C$. parasitica libraries was generated with primers that corresponded to highly conserved regions of $\mathrm{G}_{\beta}$ homologues of human (Fong et al. 1986, 1987; Levine et al. 1990; von Weizsacher et al. 1992), Drosophila (Yarfitz et al. 1988), and Dictyostelium (Lilly 1993) origin according to considerations of Gallagher and Gautam (1994). The sense primer consisted of the sequence $5^{\prime}$-AT(ATC)TA(TC)GC (GATC)ATGCA(TC)TGG-3' corresponding to the amino acid sequence IYAMHW (residues 58 to 63 of the human $\beta 1$ sequence) (Gallagher and Gautam 1994) (Fig. 2). The antisense primer corresponded to the sequence GHDNRV at positions 310 to 315 and consisted of the sequence $5^{\prime}$-AC(GATC)C (GT)(GA)TT(GA)TC(GA)TG(GATC)CC-3' (Fig. 2). PCR was performed with the GeneAmp kit (Perkin Elmer, Branchburg, NJ), using $100 \mathrm{ng}$ of $C$. parasitica cDNA as template with the following parameters: $94^{\circ} \mathrm{C}, 0.5 \mathrm{~min} ; 42^{\circ} \mathrm{C}, 1 \mathrm{~min}$; $72^{\circ} \mathrm{C}, 2 \mathrm{~min}, 30$ cycles. The major product, a 779-bp amplicon, was gel purified and cloned into the pCRII vector (Invitrogen, Carlsbad, CA) for further characterization and generation of the hybridization probe.

\section{Nucleic acid preparation and analysis.}

Total nucleic acids were extracted from approximately $3 \mathrm{~g}$ of $C$. parasitica mycelia grown on cellophane-covered PDA plates as described (Choi et al. 1992). Genomic DNA was prepared by treating the total nucleic acids with RNase A. RNA used for Northern analysis was prepared by $\mathrm{LiCl}$ precipitation (Choi et al. 1992). Standard protocols were used for both DNA and RNA blotting analyses with slight modifications (Sambrook et al. 1989). Ten micrograms of genomic DNA was used for Southern analysis after digestion with PstI. Each DNA digest was separated on a $1 \%$ agarose gel. For Northern analysis, $15 \mu \mathrm{g}$ of LiCl-precipitated RNA was separated on a formaldehyde-1.4\% agarose gel. Both DNA and RNA were transferred to Nytran Plus membranes (Schleicher and Schuell, Keene, NH) after gel elecrophoresis. Hybridization and washing of membranes were performed under stringent conditions $(1 \mathrm{M} \mathrm{NaCl}, 10 \%$ sodium dextran sulfate, $1 \%$ sodium dodecyl sulfate (SDS) at $65^{\circ} \mathrm{C}$ for hybridization; $0.1 \times$ $\mathrm{SSC}(1 \times \mathrm{SSC}$ is $0.15 \mathrm{M} \mathrm{NaCl}$ plus $0.015 \mathrm{M}$ sodium citrate), $0.1 \% \mathrm{SDS}$ at $65^{\circ} \mathrm{C}$ for washing). Northern analysis involved the additional step of stripping membranes after the first hybridization and hybridization with a probe specific for $\beta$ tubulin mRNA to monitor the amount of RNA in each well.

\section{Transformation-mediated gene disruption and phenotypic characterization.}

A $c p g b-1$ disruption vector was constructed by modifying a 3.4-kb Pst I-Pst I fragment of a genomic clone containing the cpgb-1 coding region and flanking sequences subcloned into pBluescript II SK+ (Stratagene, La Jolla, CA). A 183-bp SacINcoI fragment, extending from the $3^{\prime}$ end of exon 1 to the $3^{\prime}$ end of intron 1, was replaced with a $2.3-\mathrm{kb}$ cassette composed of the $E$. coli hygromycin phosphotransferase gene $(h p h)$ flanked by the A. nidulans $\operatorname{trpC}$ promoter and terminator. A DNA fragment released by double digestion with SpeI (located within the pBluescript multiple cloning sequence upstream of the $P$ stI site) and $P v u I I$ (located within exon 4 of the $c p g b-1$ gene) was used for transformation of spheroplasts prepared from $C$. parasitica strain EP155.

Each hygromycin-resistant transformant was reduced to nuclear homogeneity by single conidial isolation. Transformants that exhibited consistent phenotypic changes relative to untransformed control colonies were further characterized for disruption of $c p g b-1$ and ectopic integration events by PCR and Southern and Northern analyses. The phenotypic consequences of $c p g b-1$ disruption were examined as recently described for $C$. parasitica mutant strains disrupted in the $\mathrm{G}_{\alpha}$ genes cpg-1 and cpg-2 (Gao and Nuss 1996). Strain growth rates were measured under three different growth conditions. Colony diameter was measured during growth on PDA $(25 \mathrm{ml}$ per $87-\mathrm{mm}$ petri dish) following inoculation of the center of the plate with a $1-\mathrm{mm}^{3}$ plug of freshly grown mycelia and incubation in a Percival (Boone, IA) environmental chamber set for a 16-h photoperiod (approximately 2,000 lx) at $25^{\circ} \mathrm{C}$. Mass was also determined for colonies grown on PDA overlaid with cellophane and in liquid PD medium. PDA/cellophane plates were inoculated and incubated as described for PDA cultures. To determine colony mass, mycelia was stripped from the cellophane membranes and directly weighed without further processing (wet weight). Liquid PD broth cultures $(50 \mathrm{ml})$ were inoculated with a single $3-\mathrm{mm}^{3}$ mycelial 
plug and incubated without stirring under the same environmental conditions as indicated for PDA plates. Hyphae were collected by filtering through Miracloth (Calbiochem, San Diego, CA), washed with distilled water, dried in a desiccator under vacuum for 2 to 3 days, and weighed (dry weight).

Disruptants were also examined microscopically. Sterile glass cover slips $(22 \times 22 \mathrm{~mm})$ were placed on PDA plates. Hyphae were allowed to grow onto and partially cover the glass surface from a small agar inoculation plug placed at the edge of a cover slip. Microscopic observations of unstained and untreated hyphae were performed with a Zeiss (Thornwood, NY) model Axiophot 2 microscope. Photographs were taken under Nomarski optics at a magnification of $\times 1,000$.

\section{Nucleotide sequence accession number.}

The GenBank accession number for the nucleotide sequence of cpgb-1 is U95139.

\section{ACKNOWLEDGMENTS}

We thank Eric Baehrecke for assistance with the microscopic examinations. This work was funded in part by a grant from the National Institutes of Health, AI40050 to D.L.N.

\section{LITERATURE CITED}

Chen, B., Gao, S., Choi, G. H., and Nuss, D. L. 1996. Extensive alternation of fungal gene transcript accumulation and elevation of G-proteinregulated cAMP levels by a virulence-attenuating hypovirus. Proc. Natl. Acad. Sci. USA 93:7996-8000.

Choi, G. H., Chen, B., and Nuss, D. L. 1995. Virus-mediated or transgenic suppression of a G-protein $\alpha$ subunit and attenuation of fungal virulence. Proc. Natl. Acad. Sci. USA 92:305-309.

Choi, G. H., Larson, T. G., and Nuss, D. L. 1992. Molecular analysis of the laccase gene from the chestnut blight fungus and selective suppression of its expression in an isogenic hypovirulent strain. Mol. Plant-Microbe Interact. 5:119-128.

Clapham, D. E., and Neer, E. J. 1993. New roles for G-protein $\beta \gamma$-dimers in transmembrane signaling. Nature 365:403-406.

Dohlman, H., Caron, R. and Lefkowitz, R. 1987. A family of receptors coupled to guanine nucleotide regulatory proteins. Biochemistry 26: 2664-2668.

Dohlman, H. G., Thorner, J., Caron, M. G., and Lefkowitz, R. J. 1991. Model systems for the study of seven-transmembrane-segment receptors. Annu. Rev. Biochem. 60:653-688.

Fong, H. K. W., Amatruda, T. T., III, Birren, B. W., and Simon, M. I. 1987. Distinct forms of the $\beta$ subunit of GTP-binding regulatory proteins identified by molecular cloning. Proc. Natl. Acad. Sci. USA 84: 3792-3796.

Fong, H. K. W., Hurley, J. B., Hopkins, R. S., Miake-Lye, R., Johnson, M. S., Doolittle, R. F., and Simon, M. I. 1986. Repetitive segmental structure of the transducin $\beta$ subunit: Homology with the $C D C 4$ gene and identification of related mRNAs. Proc. Natl. Acad. Sci. USA 83: 2162-2166.

Gallagher, C., and Gautam, N. 1994. Design of oligonucleotide probes for molecular cloning of $\beta$ and $\gamma$ subunits. Methods Enzymol. 237: 471-482.

Gao, S., and Nuss, D. L. 1996. Distinct roles for two G protein $\alpha$ subunits in fungal virulence, morphology, and reproduction revealed by targeted gene disruption. Proc. Natl. Acad. Sci. USA 93:14122-14127.

Gilman, A. G. 1987. G proteins: Transducers of receptor-generated signals. Annu. Rev. Biochem. 56:615-649.

Hamm, H. E., and Gilchrist, A. 1996. Heterotrimeric G proteins. Curr. Opin. Cell Biol. 8:189-196.

Hermouet, S., Murakami, T., and Spiegel, A. M. 1993. Stable changes in expression or activation of G protein $\alpha_{i}$ or $\alpha_{q}$ subunits affect the expression of both $\beta_{1}$ and $\beta_{2}$ subunits. FEBS Lett. 327:183-188.

Herskowitz, I. 1987. MAP kinase pathway in yeast: For mating and more. Cell 50:995-996.

Hillman, B. I., Shapira, R., and Nuss, D. L. 1990. Hypovirulenceassociated suppression of host functions in Cryphonectria parasitica can be partially relieved by high light intensity. Phytopathology 80: 950-956.

Isshiki, T., Mochizuki, N., Maeda, T., and Yamamoto, M. 1992. Characterization of a fission yeast gene, gpa2 that encodes a $G_{\alpha}$ subunit in- volved in the monitoring of nutrition. Genes Dev. 6:2455-2462.

Ivey, F. D., Hodge, P. N., Turner, G. E., and Borkovich, K. A. 1996. The $\mathrm{G}_{\alpha \mathrm{i}}$ homologue gna- 1 controls multiple differentiation pathways in Neurospora crassa. Mol. Biol. Cell 7:1283-1297.

Kim, D. U., Park, S. K., Chung, K. S., Choi, M. U., and Yoo, H. S. 1996. The G protein $\beta$ subunit Gpb1 of Schizosaccharomyces pombe is a negative regulator of sexual development. Mol. Gen. Gent. 252:20-32.

Kozak, K. R., Foster, L. M., and Ross, I. K. 1995. Cloning and characterization of a $\mathrm{G}$ protein $\alpha$-subunit-encoding gene from the basidiomycete, Coprinus congregatus. Gene 163:133-137.

Lambright, D. G., Sondek, J., Bohm, A., Skiba, N. P., Hamm, H. E., and Sigler, P. B. 1996. The $2.0 \AA$ crystal structure of a heterotrimeric G protein. Nature 379:311-319.

Levine, M. A., Smallwood, P. M., Moen, P. T., Helman, L. J., and Ahn, T. G. 1990. Molecular cloning of $\beta 3$ subunit, a third form of the G protein $\beta$-subunit polypeptide. Proc. Natl. Acad. Sci. USA 87:2329-2333.

Lilly, P., Wu, L., Welker, D. L., and Devreotes, P. N. 1993. A G-protein $\beta$ subunit is essential for Dictyostelium development Genes Dev. 7: 986995.

Nuss, D. L. 1996. Using hypoviruses to probe and perturb signal transduction processes underlying fungal pathogenesis. Plant Cell 8:1845-1853.

Regenfelder, E., Spellig, T., Hartmann, A., Lauenstein, S., Bolker, M., and Kahmann, R. 1997. G proteins in Ustilago maydis: Transmission of multiple signals? EMBO J. 16:1934-1942.

Rudolph, U., Spicher, K., and Birnbaumer, L. 1996. Adenylyl cyclase inhibition and altered $\mathrm{G}$ protein subunit expression and ADP-ribosylation patterns in tissue and cells from $\mathrm{G}_{\mathrm{i} 2 \alpha}-/$ - mice. Proc. Natl. Acad. Sci. USA 93:3209-3214.

Sadhu, C., Hoekstra, D., McEachern, M. J., Reed, S. I., and Hicks, J. B. 1992. A G-protein $\alpha$ subunit from asexual Candida albicans functions in the mating signal transduction pathway of Saccharomyces cerevisiae and is regulated by the $\alpha 1-\alpha 2$ receptor. Mol. Cell. Biol. 12: 1977-1985.

Sambrook, J., Fritsch, E. F., and Maniatis, T. A. 1989. Molecular Cloning: A Laboratory Manual. 2nd ed. Cold Spring Harbor Laboratory, Cold Spring Harbor, NY.

Sanger, F., Nicklen, S., and Coulson, A. R. 1977. DNA sequencing with chain-terminating inhibitors. Proc. Natl. Acad. Sci. USA 74:5463-5467.

Savinon-Tejeda, A. L., Ongay-Larios, L., and Coria, R. 1996. Isolation of a gene encoding a $\mathrm{G}$ protein $\alpha$ subunit involved in the regulation of cAMP levels in the yeast Kluyveromyces lactis. Yeast 12:1125-1133.

Smulian, A. G., Ryan, M., Staben, C., and Cushion, M. T. 1996. Signal transduction in Pneumocystis carinii: Characterization of the gene (pcg1) encoding the alpha subunit of the G protein (PCG1) of Pneumocystis carinii and Pneumocystis carinii ratti. Infect. Immun. 64: 691-701.

Sondek, J., Bohm, A., Lambright, D. G., Hamm, H. E., and Sigler, P. B. 1996. Crystal structure of a GA protein $\beta \gamma$ dimer at $2.1 \AA$ resolution. Nature 379:369-374.

Tolkacheva, T., McNamara, P., Piekarz, E., and Courchesne, W. 1994. Cloning of a Cryptococcus neoformans gene, GPA1, encoding a Gprotein $\alpha$-subunit homolog. Infect. Immun. 62:2849-2856.

Turner, G. E., and Borkovich K. A. 1993. Identification of a G protein $\alpha$ subunit from Neurospora crassa that is a member of the Gi family. J. Biol. Chem. 268:14805-14811.

von Weizsacker, E., Strathmann, M. P., and Simon, M. I. 1992. Diversity among the beta subunits of heterotrimeric GTP-binding proteins: Characterization of a novel beta-subunit cDNA. Biochem. Biophys. Res. Commun. 183:350-356.

Wang, P., and Nuss, D. L. 1995. Induction of a Cryphonectria parasitica cellobiohydrolase I gene is suppressed by hypovirus infection and regulated by a GTP-binding-protein-linked signaling pathway involved in fungal pathogenesis. Proc. Natl. Acad. Sci. USA 92:11529-11533.

Whiteway, M., Hougan, L., Dignard, D., Thomas, D. Y., Bell, L., Saari, G. C., Grant, F. J., O'Hara, P., and MacKay, V. L. 1989. The STE4 and STE18 genes of yeast encode potential $\beta$ and $\gamma$ subunits of the mating factor receptor-coupled $\mathrm{G}$ protein. Cell 56:467-477.

Yarfitz, S., Provost, N. M., and Hurley, J. B. 1988. Cloning of a Drosophila melanogaster guanine nucleotide regulatory protein $\beta$-subunit gene and characterization of its expression during development. Proc. Natl. Acad. Sci. USA 85:7134-7138.

Yoder, O. C., and Turgeon, B. G. 1996. Genetic analysis of molecules required for fungal pathogenesis to plants. J. Genet. 75:425-440.

Yu, J. H., Wieser, J., and Adams, T. H. 1996. The Aspergillus FlbA RGS domain protein antagonizes $G$ protein signaling to block proliferation and allow development. EMBO J. 15:5184-5190. 